\title{
Pesquisas na internet: uma análise das competências digitais de estudantes precoces e/ou com comportamento dotado*
}

\section{Internet research: an analysis of the digital competences of gifted students}

\author{
Ketilin Mayra Pedro** \\ Miguel Cláudio Moriel Chacon***
}

\begin{abstract}
RESUMO
Com a disseminação das Tecnologias Digitais da Informação e Comunicação (TDIC) e a facilidade de acesso à internet, não podemos ignorar que os estudantes de hoje estão imersos em uma cultura digital, marcada pela interatividade e por um fluxo corrente de informações. Pensando nas habilidades destes estudantes em buscar, selecionar e compartilhar informações, é possível refletir e investigar a maneira como os estudantes precoces e/ou com comportamento dotado (PCD) relacionam-se com as TDIC e o grande volume de informações disponíveis na internet. Nessa perspectiva, é necessário identificar as habilidades que são específicas destes estudantes, e aquelas que são comuns a todos os nativos digitais para que possamos orientá-los e ajudá-los a desenvolver competências digitais. O objetivo deste estudo é verificar se estudantes com e sem PCD apresentam competências digitais relacionadas ao tratamento da informação. Trata-se de estudo comparativo entre estudantes PCD e estudantes de desenvolvimento padrão que frequentam o ensino fundamental. Com base nos resultados encontrados, observamos que a maioria dos estudantes, de ambos os grupos, não apresentaram preocupações com as fontes de pesquisas utilizadas e exploraram de maneira insuficiente os recursos disponibilizados pelos sites de pesquisa. Ressaltamos que a busca
\end{abstract}

DOI: $10.1590 / 0104-4060.50335$ (CAPES).

* Apoio Financeiro da Coordenação de Aperfeiçoamento de Pessoal de Nível Superior

** Universidade do Sagrado Coração. Bauru, São Paulo, Brasil. R. Irmã Arminda, 10-50. Jardim Brasil. CEP: 17011-160. E-mail: ketilinp@yahoo.com.br

*** Universidade Estadual Paulista Júlio de Mesquita Filho. Marília, São Paulo, Brasil. Campus Marília. Av. Higino Muzi Filho, nº 737. Mirante. CEP: 17525-900. E-mail: profmcmchacon (a)gmail.com 
de informações é umas das habilidades mais básicas dentro da competência digital, visto que uma pesquisa bem realizada leva a fontes mais seguras de pesquisa, revelando uma maior confiabilidade para a informação encontrada.

Palavras-chave: Precocidade. Superdotação. Competências digitais. Pesquisas na internet.

\begin{abstract}
With the spread of the Information and Communications Technology (ICT) and the ease of access to the internet, we cannot ignore that today's students are immersed in a digital culture, marked by interactivity and a flow of information. Considering these students' abilities to search, select, and share information, it is possible to think about and investigate how gifted students relate to ICT and the large volume of information available on the internet. Through this perspective, it is necessary to identify the skills that are specific to these students and those that are common to all digital natives, so that we can guide them and help them develop digital skills. The aim of this study is to verify if gifted and non-gifted students present digital competences related to information processing. This is a comparative study between gifted students and standard development students attending elementary school. Based on the results, we have found that most students in both groups had no concerns about the sources of research used and had not exploited enough the resources available on research sites. We emphasize that the search for information is one of the most basic skills within the digital competence, since a well-conducted research leads to safer sources of research, granting greater reliability for the information found.
\end{abstract}

Keywords: Precocity. Giftedness. Digital competencies. Internet research.

\title{
Introdução
}

Com a disseminação das Tecnologias Digitais da Informação e Comunicação (TDIC) e a facilidade de acesso à internet que temos atualmente, não podemos ignorar que os estudantes de hoje estão imersos em uma cultural digital. Eles apresentam características e comportamentos diferenciados e são influenciados pelo enorme fluxo de informações disponíveis na internet e pela interatividade imediata proporcionada pelos recursos digitais. 
Nossa experiência no Programa de Atenção a Estudantes Precoces com Comportamento Superdotado (PAPCS), vinculado ao Departamento de Educação Especial da Faculdade de Filosofia e Ciências (FFC), da Universidade Estadual Paulista "Júlio de Mesquita Filho" - Unesp, Campus de Marília, coordenado pelo Professor Doutor Miguel Cláudio Moriel Chacon, evidencia que os estudantes precoces e/ou com comportamento dotado $(\mathrm{PCD})^{1}$ estão cada vez mais inseridos no mundo digital e apresentam habilidades para o uso dos mais variados recursos tecnológicos para o entretenimento e comunicação.

De acordo com a Política Nacional de Educação Especial na Perspectiva da Educação Inclusiva, são considerados estudantes superdotados aqueles que

[...] demonstram potencial elevado em qualquer uma das seguintes áreas, isoladas ou combinadas: intelectual, acadêmica, liderança, psicomotricidade e artes. Também apresentam elevada criatividade, grande envolvimento na aprendizagem e realização de tarefas em áreas de seu interesse. (BRASIL, 2008, p. 15).

Assim como os demais estudantes, aqueles que apresentam PCD são influenciados cotidianamente pela sociedade da informação e pela cultura digital. Segundo Palfrey e Gasser (2011), os estudantes que nasceram nesta cultura podem ser nomeados como nativos digitais. Nesse sentido, acreditamos que, para a realidade brasileira atual, podemos considerar como nativos digitais aqueles que nasceram após 1990, visto que a internet começou a ser popularizada no Brasil a partir de 1992.

Pensando nas habilidades dos nativos digitais em buscar, selecionar e compartilhar informações, é possível refletir e investigar a maneira como os estudantes PCD relacionam-se com as TDIC e o grande volume de informações disponíveis na internet, sendo que são primordiais para o desenvolvimento adequado e satisfatório dos estudantes. Segundo Palfrey e Gasser (2011, p. 203), "[...] nossos nativos digitais vão ter um enorme sucesso se conseguirem sintetizar as informações que encontram no mundo digital; caso contrário, vão afundar no excesso de informações".

As habilidades necessárias para uma utilização consciente e positiva das TDIC são denominadas como competências digitais. Segundo Lueg (2014), estas

1 Neste trabalho utilizaremos a nomenclatura precoce e/ou com comportamento dotado para nomear aqueles estudantes que apresentam: habilidade acima da média, altos níveis de criatividade e envolvimento com a tarefa (RENZULLI, 2014). Destacamos que compreendemos que a precocidade e os comportamentos dotados fazem parte de um fenômeno maior chamado superdotação. 
podem ser definidas como: a mobilização de habilidades que permitem buscar, selecionar criticamente e processar a informação; capacidade de se comunicar usando diferentes suportes tecnológicos e digitais; atuar com responsabilidade, respeitando as normas estabelecidas e aproveitando estas ferramentas para informar-se, aprender, resolver problemas e comunicar-se. A competência digital permite que o usuário vá além da utilização técnica e instrumental das TDIC, mas seja capaz de aproveitar todo o potencial informativo que elas oferecem.

Nessa perspectiva, acreditamos que as TDIC são valiosas ferramentas intelectuais para enriquecimento de estudantes PCD. No entanto, é necessário identificar as habilidades que são específicas destes estudantes e aquelas que são comuns a todos os nativos digitais para que possamos orientá-los e ajudá-los a desenvolver competências digitais. Sendo assim, o objetivo deste estudo é verificar se estudantes com e sem PCD apresentam competências digitais relacionadas ao tratamento da informação.

\section{Método}

Trata-se de um recorte de uma pesquisa de doutorado que descreve comparativamente o uso que os estudantes com e sem precocidade e comportamento dotado, dos anos iniciais e finais do ensino fundamental, fazem das TDIC.

O grupo de estudantes precoces e dotados (G1) foi composto com base nos dados do PAPCS. A partir dos estudantes deste grupo, foram elencadas as escolas em que buscamos os participantes do grupo comparativo (G2), cujas características eram pareadas aos alunos do G1 (gênero, idade, ano escolar e condições de acesso as TDIC), exceto as variáveis precocidade e superdotação. O Quadro 1 apresenta os pareamentos dos estudantes participantes.

Todos os estudantes participantes da pesquisa realizaram um Programa de Atividades Dirigidas que contemplava a utilização da internet e variados softwares. Neste estudo apresentaremos os dados referentes à atividade "Pesquisa na Internet". 
QUADRO 1 - PAREAMENTO DOS GRUPOS 1 E 2

\begin{tabular}{|c|c|c|c|c|}
\hline G1 & G2 & Gênero & Idade & Ano Escolar \\
\hline CV & R & Masculino & 8 & $3^{\text {o }}$ \\
\hline C & G & Feminino & 10 & $5^{\text {o }}$ \\
\hline DA & MR & Masculino & 8 & $2^{\text {o }}$ \\
\hline ES & RZ & Masculino & 11 & $5^{\text {o }}$ \\
\hline FB & LM & Masculino & 10 & $5^{\text {o }}$ \\
\hline FP & L & Masculino & 6 & $1^{\text {o }}$ \\
\hline M & PH & Masculino & 11 & $5^{\text {o }}$ \\
\hline PD & IA & Masculino & 11 & $5^{\circ}$ \\
\hline VA & JP & Masculino & 11 & $5^{\circ}$ \\
\hline VH & FA & Masculino & 10 & $4^{\circ}$ \\
\hline V & IC & Feminino & 6 & $1^{\text {o }}$ \\
\hline DE & LL & Masculino & 14 & $9^{\text {o }}$ \\
\hline BG & N & Feminino & 11 & $6^{\circ}$ \\
\hline D & TS & Masculino & 11 & $6^{\circ}$ \\
\hline GS & AJV & Feminino & 13 & $8^{\circ}$ \\
\hline IS & AJ & Feminino & 13 & $8^{\text {o }}$ \\
\hline PE & W & Masculino & 13 & $8^{\text {o }}$ \\
\hline RC & TG & Masculino & 13 & $8^{\text {o }}$ \\
\hline
\end{tabular}

FONTE: Elaboração Própria.

Esta atividade foi subdividida em 6 partes: 1. acessar um navegador (Chrome, Internet Explorer ou Mozilla); 2. acessar um site de pesquisa; 3. realizar uma pesquisa (tema livre); 4. transferir o conteúdo da pesquisa para o Microsoft Office Word; 5. realizar uma busca por imagens; e 7. salvar a imagem. A elaboração dessa atividade baseou-se principalmente na competência digital associada ao tratamento da informação: aprender a buscar informação - desenvolver estratégias de busca e seleção (MONEREO; AGUSTÍ, 2010).

Para fins de análise dos dados, comparamos o desempenho dos estudantes do G1 e G2 durante a realização das atividades e realizamos a análise com base na literatura pertinente da área.

\section{Resultados e Discussões}

O Quadro 2 apresenta a síntese do desenvolvimento da atividade pelos estudantes dos anos iniciais do ensino fundamental. 


\section{QUADRO 2 - DESENVOLVIMENTO DA ATIVIDADE 5 - ANOS INICIAIS}

\begin{tabular}{|c|c|}
\hline \multicolumn{2}{|c|}{ Atividade 5 - Pesquisa na internet (anos iniciais) } \\
\hline G1 & G2 \\
\hline \multicolumn{2}{|c|}{$\mathbf{1}^{\circ}$ ano } \\
\hline $\begin{array}{l}\text { FP fez uma busca sobre "como usar a varinha } \\
\text { de negação do Yogbox", essa pesquisa tem re- } \\
\text { lação com o jogo Minecraft. Sua busca não } \\
\text { apresentou os resultados que ele queria, sen- } \\
\text { do assim, modificou a palavra chave para } \\
\text { "Dicas do Yogbox". Quando perguntei como } \\
\text { seleciona os sites para entrar, ele não soube } \\
\text { responder; mas observei que ele entra aleato- } \\
\text { riamente e se o site não oferta o que ele precisa, } \\
\text { retorna para a página de pesquisa. FP copiou } \\
\text { e colou o conteúdo no Word, mas não soube } \\
\text { salvar a figura diretamente da internet. }\end{array}$ & $\begin{array}{l}\text { L acessou o navegador de internet com aju- } \\
\text { da e fez uma busca sobre Venom, Feromonas e } \\
\text { Monark (personagens do jogo Minecraft). Ao } \\
\text { ser indagado sobre como seleciona o site que } \\
\text { irá acessar, o estudante disse que geralmente } \\
\text { acessa vídeos porque é mais fácil. L aluno não } \\
\text { soube transferir o conteúdo para o Word e sal- } \\
\text { var a figura pesquisada. }\end{array}$ \\
\hline $\begin{array}{l}\text { V precisou de esclarecimento e ajuda para } \\
\text { acessar o navegador. V fez uma busca sobre a } \\
\text { Peppa Pig e ficou encantada com os vídeos que } \\
\text { surgiram na página de resultados. Não reali- } \\
\text { zou as demais atividades. }\end{array}$ & $\begin{array}{l}\text { IC precisou de esclarecimento e ajuda para } \\
\text { acessar o navegador. IC também fez uma bus- } \\
\text { ca sobre a Peppa Pig. Não realizou as demais } \\
\text { atividades. }\end{array}$ \\
\hline \multicolumn{2}{|c|}{$2^{\circ}$ ano } \\
\hline $\begin{array}{l}\text { DA procurou pelo tema Meio Ambiente, quan- } \\
\text { do indagado sobre como selecionava o site, DA } \\
\text { disse que sempre lê o resumo abaixo do site } \\
\text { antes de acessar. DA precisou de ajuda para } \\
\text { colar o conteúdo no } \text { Word, realizou a busca de } \\
\text { imagens e salvou o arquivo corretamente. }\end{array}$ & $\begin{array}{l}\text { MR fez uma busca por futebol, quando inda- } \\
\text { gado sobre como escolhe o site que irá acessar, } \\
\text { M disse que lê o resumo e que costuma abrir } \\
\text { vários sites. Precisou de ajuda para copiar e } \\
\text { colar o conteúdo e a imagem no Word. M sal- } \\
\text { vou o arquivo corretamente. }\end{array}$ \\
\hline \multicolumn{2}{|c|}{$3^{\circ}$ ano } \\
\hline $\begin{array}{l}\text { CV fez uma busca por insetos. Ao ser indagado } \\
\text { sobre como seleciona o site antes de entrar, o } \\
\text { estudante disse que geralmente entra em vá- } \\
\text { rios até encontrar o que quer e que geralmente } \\
\text { consulta a Wikipédia. CV precisou de esclare- } \\
\text { cimento para copiar e colar o texto no Word, } \\
\text { realizou a busca de imagens e salvou o arquivo } \\
\text { corretamente. }\end{array}$ & $\begin{array}{l}\mathrm{R} \text { acessou o Google com ajuda e realizou uma } \\
\text { busca pelo personagem Superman. Quando } \\
\text { perguntado sobre como seleciona o site, o estu- } \\
\text { dante falou que abre os sites em novas guias e } \\
\text { que abre vários até encontrar o que precisa. } \\
\mathrm{R} \text { transferiu o conteúdo para o Word correta- } \\
\text { mente e não realizou uma busca de figuras. }\end{array}$ \\
\hline \multicolumn{2}{|c|}{$4^{0}$ ano } \\
\hline $\begin{array}{l}\text { VH pesquisou sobre frações. Indaguei como } \\
\text { ele selecionava o site, VH afirmou que sem- } \\
\text { pre escolhe a Wikipédia, embora ela seja uma } \\
\text { enciclopédia aberta em que qualquer um pode } \\
\text { postar conteúdo. VH disse que esse site sempre } \\
\text { tem as informações e figuras que ele precisa. } \\
\text { VH não transferiu o conteúdo para o Word. }\end{array}$ & $\begin{array}{l}\text { FA fez uma busca por "dados do Pterodáctilo" } \\
\text { e precisou de ajuda para transferir o conteúdo } \\
\text { para o Word. FA relatou que escolhe os sites } \\
\text { aleatoriamente. O estudante fez uma busca } \\
\text { por imagens e as salvou corretamente. }\end{array}$ \\
\hline
\end{tabular}


(conclusão)

\begin{tabular}{|c|c|}
\hline \multicolumn{2}{|c|}{$5^{\circ}$ ano } \\
\hline $\begin{array}{l}\text { C fez uma busca por Pokémon e disse que para } \\
\text { selecionar o site ela geralmente lê os resumos } \\
\text { que ficam abaixo do endereço do site, também } \\
\text { demonstrou compreender a função dos hiper- } \\
\text { textos na página da internet. C precisou de } \\
\text { ajuda para transferir o conteúdo para o Word } \\
\text { e de esclarecimento para salvar a imagem. }\end{array}$ & $\begin{array}{l}\text { G fez uma busca sobre fatos científicos e afir- } \\
\text { mou que sempre abre o primeiro site listado. } \\
\text { Quando solicitei que transferisse o conteúdo } \\
\text { para o Word, ela salvou a página da web. G não } \\
\text { conseguiu salvar somente a figura. }\end{array}$ \\
\hline $\begin{array}{l}\text { ES fez uma busca por curiosidades do } M c D o- \\
\text { nalds e afirmou que costuma acessar a Wikipé- } \\
\text { dia, que esse é o melhor site. Embora a escola } \\
\text { recomende outros sites, ele sempre opta pela } \\
\text { Wikipédia ou sites oficiais quando está procu- } \\
\text { rando por jogos ou produtos com marcas. ES } \\
\text { realizou as demais atividades corretamente } \\
\text { e afirmou que as palavras que estavam na cor } \\
\text { azul (links) eram as palavras mais difíceis. }\end{array}$ & $\begin{array}{l}\text { RZ fez uma busca por Halloween e disse que } \\
\text { quando faz pesquisas para a escola geralmen- } \\
\text { te utiliza a Wikipédia. RZ não sabe para que } \\
\text { serve os links do texto, nem como retirá-los } \\
\text { quando o texto é transferido para o Word. O } \\
\text { aluno fez a busca por imagens e precisou de } \\
\text { esclarecimento para salvá-la. }\end{array}$ \\
\hline $\begin{array}{l}\text { FB fez uma busca por ET e disse que para se- } \\
\text { lecionar o site lê o título e o resumo de cada } \\
\text { um. FB realizou todas as atividades correta- } \\
\text { mente. }\end{array}$ & $\begin{array}{l}\text { LM fez uma pesquisa sobre o desenho Dra- } \\
\text { gonball } Z \text { e disse que para selecionar o site } \\
\text { verifica a classificação realizada por outros } \\
\text { internautas, também lê o resumo do site. LM } \\
\text { realizou todas as atividades corretamente. }\end{array}$ \\
\hline $\begin{array}{l}\text { M fez uma busca sobre a máquina do tempo } \\
\text { utilizada no filme De volta para o Futuro e afir- } \\
\text { mou que sempre acessa o Wikipédia por ser } \\
\text { mais fácil e rápido. M não soube transferir o } \\
\text { conteúdo para o Word, disse que, quando pre- } \\
\text { cisa para trabalhos escolares, a mãe o auxilia. }\end{array}$ & $\begin{array}{l}\text { PH fez uma busca por "Sílvio Santos". Dis- } \\
\text { se que sempre lê os resumos abaixo do link } \\
\text { para escolher qual acessar. PH realizou as } \\
\text { demais atividades corretamente, embora tenha } \\
\text { afirmado que geralmente não copia o conteúdo, } \\
\text { mas imprime direto da internet. }\end{array}$ \\
\hline $\begin{array}{l}\text { PD fez uma busca por "Lamborghini Galhar- } \\
\text { do". Para selecionar o site, o aluno costuma ler } \\
\text { o resumo que fica abaixo do link. PD afirmou } \\
\text { que costuma clicar em cima das palavras azuis } \\
\text { (links) para ter mais informações. PD realizou } \\
\text { as demais atividades corretamente. }\end{array}$ & $\begin{array}{l}\text { IA fez uma busca pelo Livro Diário de um } \mathrm{Ba} \text { - } \\
\text { nana. Ao ser indagado sobre como seleciona } \\
\text { o site que vai acessar, ele afirmou que sempre } \\
\text { entra no primeiro site listado. IA realizou as } \\
\text { demais atividades corretamente. }\end{array}$ \\
\hline $\begin{array}{l}\text { VA fez uma pesquisa sobre o desenho Dragon- } \\
\text { ball Z. Quando perguntei sobre como seleciona } \\
\text { os sites, VA afirmou que se preocupa mais } \\
\text { com isso se é para atividades escolares. A pro- } \\
\text { fessora do estudante ensinou que alguns sites, } \\
\text { como Wikipédia devem ser evitados, uma vez } \\
\text { que o conteúdo não é confiável e pode ser alte- } \\
\text { rado. VA soube selecionar o conteúdo e transfe- } \\
\text { rir corretamente para o Word e no momento de } \\
\text { salvar a figura, salvou a página da web. }\end{array}$ & $\begin{array}{l}\text { JP fez uma busca pela biografia de Roberto Bo- } \\
\text { laños (o ator havia falecido no fim de semana } \\
\text { que precedeu a realização da atividade). JP dis- } \\
\text { se que para escolher o site que vai acessar sem- } \\
\text { pre lê os resumos que ficam embaixo. O aluno } \\
\text { acessou a Wikipédia e disse que os hipertextos } \\
\text { "tem algumas informações a mais". JP soube } \\
\text { selecionar o conteúdo e transferir corretamente } \\
\text { para o Word, mas teve dificuldades para salvar } \\
\text { a figura. }\end{array}$ \\
\hline
\end{tabular}

FONTE: Elaboração própria. 
Considerando inicialmente os estudantes do primeiro ano, verificamos que demonstraram familiaridade com a navegação na internet, de modo que, mesmo aqueles que não dominavam o sistema de escrita, foram capazes de realizar a pesquisa. Marques (2015), em seu estudo, conclui que a cada ano o número de crianças que começam a acessar a internet, ainda na primeira infância, aumenta significativamente. Essa circunstância pode ser associada à cultura digital, que tem permeado a vida de toda a sociedade, e a facilidade de acesso às TDIC e à internet, em espaços variados, como escolas, bibliotecas, centros comunitários etc.

Observamos que as temáticas pesquisadas por alguns estudantes versavam sobre desenhos animados, personagens, jogos ou programas que estavam em evidência, na época da coleta de dados, tais como os desenhos animados Peppa Pig, Minecraft, Superman, Pokémon e Dragon Ball Z. Notamos também interesses parecidos entre estudantes do primeiro ano, de ambos os grupos: FP e L pesquisaram sobre o jogo Minecraft; V e IC, a respeito da Peppa Pig. O interesse por esses temas pode ser justificado pela integração das TDIC à rotina dos estudantes, de maneira que os utilizam como se fossem "extensões de si mesmos" e geralmente atribuem a estas a função de entretenimento (PESCADOR, 2012).

Estudantes como DA, CV e VH (pertencentes ao G1), FA e G (pertencentes ao G2) diferenciaram-se ao realizar pesquisas com temas que fugiram da abordagem de entretenimento. Observamos que os estudantes do G1 buscaram por assuntos ligados às suas áreas de interesse e domínio, dados estes que corroboram os estudos de Ahmad et al. (2014). Por sua vez, os estudantes do G2 procuraram assuntos que estavam sendo explorados no ambiente escolar, fato também percebido e analisado na atividade sobre criação de pastas.

Em relação à utilização das palavras-chave, destacamos os estudantes $\mathrm{FPe}$ ES, do G1, e o estudante FA, do G2, os quais, no momento de definirem a palavra-chave, indicaram um termo antes do assunto principal, como, por exemplo: "dados do Pterodáctilo". Tal estratégia auxilia a filtragem das informações e faz com que a pesquisa tenha um melhor direcionamento.

A escolha adequada das palavras-chave faz parte da competência digital referente ao tratamento da informação. $\mathrm{Na}$ verdade, a maioria dos estudantes executa impulsivamente a pesquisa caracterizada pela tentativa e erro, sendo que não exploram de forma mais refinada as ferramentas de pesquisa e não atentam à seleção prévia das palavras-chave.

Sobre o site de pesquisa usado, todos os estudantes acessaram a página do Google e apresentaram estratégias variadas para selecionar os resultados. Seis estudantes (G1=4 e G2=2) fizeram uso da Wikipédia como fonte de busca para a pesquisa feita. Embora alguns reconheçam que esse site é uma enciclopédia aberta e cujo conteúdo disponível nem sempre é confiável, os estudantes 
a empregam por constituir um recurso prático e rápido, visto que geralmente é um dos primeiros sites listados ao se realizar uma busca.

De acordo com Monereo e Agustí (2010), os usuários que adotam somente a Wikipédia como fonte de busca podem ser categorizados como buscadores ativos, pois procuram a informação de maneira intencional, mas restringem suas pesquisas a uma única fonte, limitando o acesso às informações mais completas e significativas.

Quando os estudantes acessavam a enciclopédia virtual Wikipédia, indagávamos se estes conheciam a funcionalidade das palavras destacadas em azul (links). Embora não soubessem nomear corretamente esse recurso, todos sabiam que, por meio dele, era possível acessar novas páginas ou obter mais informações. Segóvia et al. (2013) consideram a busca de informações uma das habilidades mais básicas dentro da competência digital, pois uma pesquisa bem realizada leva a fontes mais seguras de pesquisa, revelando uma maior confiabilidade para a informação encontrada.

Ainda sobre as estratégias utilizadas para selecionar os resultados da pesquisa, oito estudantes $(\mathrm{G} 1=4$ e $\mathrm{G} 2=4)$ relataram ler os resumos localizados abaixo do endereço de cada site, antes de acessá-lo, tendo uma ideia prévia do conteúdo que seria encontrado. Essa estratégia demonstra uma preocupação inicial em não empreender uma busca aleatória, mas optar por resultados que estejam mais relacionados com o tema que procuram. Dois estudantes do G2 afirmaram que entram no primeiro site listado, sem se preocuparem com a fonte que estão acessando.

Além da confiabilidade da informação, a seleção dos sites de pesquisa se faz importante para que os estudantes não sejam influenciados pelas questões mercadológicas que envolvem a divulgação de determinados sites nos portais de busca. Alguns autores alertam que há páginas previamente programadas para serem listadas em determinadas pesquisas (BUIM ARENA, 2015).

No que concerne à ação de "copiar e colar" o conteúdo pesquisado para um documento do Microsoft Office Word, o desempenho dos estudantes foi equilibrado, já que oito estudantes de cada grupo realizaram essa atividade. Embora esse comando de "copiar e colar" esteja presente na maioria das atividades efetuadas no computador e/ou dispositivos móveis, é preciso pensar que este tem sido o centro da problemática em relação à cópia desenfreada de conteúdos, seja no ensino básico, seja no superior (SANTAROSA; CONFORTO, 2012). Além da problemática sobre a não referência das fontes utilizadas, a ação de "copiar e colar" mecaniza o ato da pesquisa, pois grande parte dos estudantes copia e cola conteúdo da internet sem ler e compreender seu conteúdo.

Dentre os estudantes do G1, cinco demonstraram cautela no momento de fazer a pesquisa e selecionar o site para ser acessado, da mesma forma quatro estudantes do G2 tiveram a mesma postura. Acreditamos que ter habilidades 
relacionadas ao tratamento da informação não se associa diretamente à presença ou não de precocidade e/ou comportamento dotado.

O Quadro 3 traz a síntese da atividade de pesquisa na internet com os estudantes dos anos finais.

\section{QUADRO 3 - DESENVOLVIMENTO DA ATIVIDADE 5 - ANOS FINAIS}

\begin{tabular}{|c|c|}
\hline \multicolumn{2}{|c|}{ Atividade 5 - Pesquisa na internet (anos finais) } \\
\hline G1 & G2 \\
\hline \multicolumn{2}{|c|}{$6^{\circ}$ ano } \\
\hline $\begin{array}{l}\text { BG acessou o Google Chrome sem dificulda- } \\
\text { des e fez a busca por meio da Barra de Ende- } \\
\text { reços. A estudante começou a digitar "Quantas } \\
\text { moléculas... e assim que apareceram as opções } \\
\text { a aluna logo clicou na primeira "Quantas molé- } \\
\text { culas de bufano existem num isqueiro". Sobre } \\
\text { a seleção dos sites de pesquisa, BG afirmou } \\
\text { sempre ler os resumos que estão abaixo dos } \\
\text { links. BG copiou o texto sem dificuldades, no } \\
\text { entanto, houve a necessidade de ajuda para } \\
\text { colar o conteúdo. Depois a estudante fez uma } \\
\text { busca por imagens (usando a aba imagens do } \\
\text { Google) e buscou por tabelas periódicas, foi } \\
\text { necessária ajuda para copiar a figura, para } \\
\text { salvar a figura não houve dificuldades. }\end{array}$ & $\begin{array}{l}\text { N acessou o Google Chrome e fez uma busca } \\
\text { pelo livro Meu pé de Laranja Lima. Sobre a se- } \\
\text { leção dos sites de pesquisa, a aluna disse que lê } \\
\text { o nome do site ou vai no primeiro, depende } \\
\text { para o que é a pesquisa. Não soube transfe- } \\
\text { rir o conteúdo para o Microsoft Office Word, } \\
\text { fez a busca corretamente por imagens e preci- } \\
\text { sou de ajuda para salvá-la. }\end{array}$ \\
\hline $\begin{array}{l}\text { D acessou o Google e fez uma busca por "mo- } \\
\text { delos de rádio". Quando indagado sobre como } \\
\text { seleciona o site de pesquisa, D afirmou que vai } \\
\text { pela aparência, escolhendo o mais bonito. } \\
\text { Não soube transferir o texto para o Word e, } \\
\text { no momento de salvar a figura, salvou o link na } \\
\text { pasta que havia criado anteriormente. }\end{array}$ & $\begin{array}{l}\text { TH acessou Google e fez uma busca pelo filme } \\
\text { Tá Chovendo Hamburguer. Sobre a seleção dos } \\
\text { sites de pesquisa, o estudante afirmou que lê o } \\
\text { resumo do site e também o seu título para } \\
\text { ver se de fato o conteúdo lhe interessa. TH } \\
\text { precisou de esclarecimento e ajuda para sele- } \\
\text { cionar o texto e transferir para o Word, realizou } \\
\text { a busca por imagens e a salvou na pasta. }\end{array}$ \\
\hline \multicolumn{2}{|r|}{$8^{\circ}$ ano } \\
\hline $\begin{array}{l}\text { GS acessou o Google e fez uma busca por "O } \\
\text { que é escassez de água". A estudante disse que } \\
\text { acessa o site sempre pelo título e verifica se } \\
\text { é adequado ou não. GS selecionou o texto e } \\
\text { precisou de esclarecimento para Colar, reali- } \\
\text { zou as demais atividades sem dificuldade. }\end{array}$ & $\begin{array}{l}\text { AJV acessou o Google e fez uma busca sobre } \\
\text { Abolição da Escravatura (disse que tinha fei- } \\
\text { to uma tarefa sobre o tema antes de vir para a } \\
\text { coleta). Ao ser indagada sobre como a aluna } \\
\text { seleciona o site, ela disse que, embora utilize } \\
\text { a Wikipédia de vez em quando, sabe que esse } \\
\text { site não é confiável, também disse que costuma } \\
\text { ler as informações que ficam abaixo do site. } \\
\text { Realizou as demais atividades sem dificuldade. }\end{array}$ \\
\hline
\end{tabular}

(continua) 
(conclusão)

\begin{tabular}{|c|c|}
\hline $\begin{array}{l}\text { IS acessou o Google e fez uma busca sobre um } \\
\text { personagem de "anime" que ela gosta. A estu- } \\
\text { dante relatou que quando realiza uma busca, } \\
\text { acessa vários sites e seleciona aquele que tem } \\
\text { todas as informações que precisa. IS realizou } \\
\text { as demais atividades sem dificuldades. }\end{array}$ & $\begin{array}{l}\text { AJ acessou o Google e fez uma busca por Anne } \\
\text { Frank. A estudante relatou que quando realiza } \\
\text { uma busca sempre entra inicialmente na Wiki- } \\
\text { pédia, caso não encontre o que precisa ela vai } \\
\text { para outros sites. AJ realizou as demais ativi- } \\
\text { dades corretamente. }\end{array}$ \\
\hline $\begin{array}{l}\text { PE acessou o Google e fez uma busca por Real } \\
\text { Madrid, quando perguntado sobre como sele- } \\
\text { ciona o site para pesquisa, o estudante disse } \\
\text { que sempre abre o primeiro que aparece por- } \\
\text { que geralmente é o mais acessado. PE realizou } \\
\text { corretamente as demais atividades. }\end{array}$ & $\begin{array}{l}\text { W fez uma busca por League of Legends utili- } \\
\text { zando o Google, ao ser indagado sobre como } \\
\text { escolhe os sites que vai entrar, o estudante re- } \\
\text { latou que o antivírus que ele utiliza (McAfee) } \\
\text { faz uma seleção prévia dos sites que são se- } \\
\text { guros, além disso, usa a opinião de amigos } \\
\text { sobre quais sites são os melhores para realizar a } \\
\text { pesquisa. W realizou as demais atividades cor- } \\
\text { retamente. }\end{array}$ \\
\hline $\begin{array}{l}\text { RC acessou o Google e fez uma busca por } \\
\text { Assassin's Creed (não recomendado para me- } \\
\text { nores de } 18 \text { anos, o estudante sabe que o jogo } \\
\text { não é apropriado, pois ele perguntou se real- } \\
\text { mente poderia fazer a busca por esse jogo). Ao } \\
\text { ser indagado sobre como seleciona o site que } \\
\text { vai acessar, afirmou que sempre abre a Wikipé- } \\
\text { dia. RC precisou de ajuda para colar o con- } \\
\text { teúdo do Word e realizou as demais atividades } \\
\text { corretamente. }\end{array}$ & $\begin{array}{l}\text { TG acessou o Google e fez uma busca sobre o } \\
\text { seriado ICarly. Ao ser questionado sobre como } \\
\text { seleciona o site que irá acessar, o aluno disse } \\
\text { que sempre opta pela Wikipédia, sendo que } \\
\text { esse sempre explica tudo. O estudante realizou } \\
\text { as demais atividades corretamente. }\end{array}$ \\
\hline \multicolumn{2}{|l|}{$\begin{array}{ll}0 & \text { ano }\end{array}$} \\
\hline $\begin{array}{l}\text { DE acessou o Google e fez uma busca por } \\
\text { Guerra Fria, o estudante relatou que sempre } \\
\text { lê o resumo dos sites antes de acessar e que } \\
\text { não confia na Wikipédia, sendo que leu infor- } \\
\text { mações neste site que não eram verdadeiras. O } \\
\text { estudante demonstrou conhecimento sobre os } \\
\text { hiperlinks e realizou as demais atividades soli- } \\
\text { citadas sem dificuldades. }\end{array}$ & $\begin{array}{l}\text { LL acessou o Google Chrome e fez uma bus- } \\
\text { ca por Anatomia Humana. Quando indagado } \\
\text { sobre como seleciona o site ao acessar, o estu- } \\
\text { dante disse que busca sempre pelos sites mais } \\
\text { conhecidos como Wikipédia, Uol e Brasil Es- } \\
\text { cola. O estudante demonstrou conhecimento } \\
\text { sobre os hiperlinks e realizou as demais ativi- } \\
\text { dades solicitadas sem dificuldades. }\end{array}$ \\
\hline
\end{tabular}

FONTE: Elaboração própria.

Sobre a temática da pesquisa realizada nessa atividade, observamos que a maioria dos estudantes optou por temáticas ligadas aos seus interesses ou aos conteúdos escolares que estavam sendo aprendidos. Apenas dois estudantes de cada grupo optaram por assuntos de entretenimento, como Real Madrid, o seriado ICarly e os jogos Assassin's Creed e League of Legends.

Salientamos que o jogo Assassin's Creed não é indicado para menores de 17 anos, por conter cenas de violência e conotação sexual. Acessar jogos ou conteúdos que não estejam compatíveis com a faixa etária dos estudantes é uma das preocupações ocasionadas pela cultura digital e a sociedade da informação, 
visto que se pode acessar qualquer conteúdo em qualquer lugar do mundo, sem nenhum tipo de censura.

Quanto aos estudantes PCD, ressaltamos que quatro realizaram pesquisas associadas às suas áreas de interesse: a estudante $\mathrm{BG}$ mostra comportamento dotado na área musical e obsessão pela parte de física e química, já D caracteriza-se como criativo-produtivo e apresenta grande interesse por aparelhos eletrônicos. Por sua vez, a estudante IS revela grande potencial para desenhos do tipo Mangá, com interesse por esse tipo de literatura, e, por fim, o estudante $\mathrm{DE}$, que é acadêmico, tem interesse e domínio sobre assuntos históricos e científicos. Ahmad et al. (2014) destacam que as TDIC apresentam grande potencial como ferramenta de aprendizagem, ressaltando que, em suas pesquisas, foram encontrados estudantes com comportamento dotado que usam sites como Google e Youtube para ampliar seus conhecimentos sobre uma determinada área.

A respeito da escolha da palavra-chave, na pesquisa, observamos que os estudantes a usaram de maneira convencional, alguns apelaram a perguntas, como, por exemplo: "Quantas moléculas de bufano existem num isqueiro"? "O que é escassez de água"? Costa (2002) aponta que, quando a seleção da palavra-chave não é adequada, é possível se correr o risco de obter um número excessivo ou reduzido de resultados, ao passo que, se adotarmos palavras-chave mais sintéticas, obteremos resultados mais precisos.

No tocante à seleção dos sites como fontes de pesquisa, verificamos que alguns estudantes dos anos finais ainda usavam sites como a Wikipédia (G1=1 e G2=4), ainda que alguns estudantes do G1 demonstrassem conhecer as fragilidades dessa enciclopédia virtual. Os demais estudantes adotaram estratégias variadas, como opinião de amigos, título do site, primeiro site listado etc., apenas quatro estudantes $(\mathrm{G} 1=2$ e $\mathrm{G} 2=2)$ afirmaram ler os resumos disponibilizados abaixo do link. Com base na classificação de Monereo e Agustí (2010), consideramos que os estudantes que utilizaram a Wikipédia como fonte de busca ainda se encontram em um estágio de buscador ativo, enquanto aqueles que empregaram estratégias de pesquisa mais elaboradas se mostram como seletivos, preocupando-se com o objetivo da pesquisa e a fonte de informação a ser acessada.

Nosso estudo detectou que os estudantes apresentam dificuldades para tratar a informação, seja nos aspectos de seleção, seja de organização ou análise. Santos (2015) reitera a necessidade de ensinarmos os nativos digitais a filtrarem o enorme número de informações que são postadas e atualizadas na rede diariamente.

A análise dessa atividade evidenciou que alguns estudantes nem sempre buscam por conteúdos adequados para a idade, muitos acessam conteúdos infantis, que não desafiam e nem agregam novos conhecimentos, enquanto outros 
optam por jogos violentos, os quais não são adequados à sua faixa etária. Tal fato demonstra que muitos não têm suas atividades no computador supervisionadas e orientadas, como também subaproveitam o potencial das tecnologias digitais.

Ainda sobre os conteúdos e temas pesquisados na internet pelos estudantes dos anos iniciais e finais do ensino fundamental, observamos que oito estudantes PCD se aproveitaram da internet para buscar assuntos de suas áreas de interesse, demonstrando reconhecer o potencial das TDIC para aquisição de novas informações.

\section{Considerações finais}

Ao longo do desenvolvimento desta atividade, observamos que a maioria dos estudantes de ambos os grupos não apresentaram preocupações com as fontes de pesquisas utilizadas e exploraram de maneira insuficiente os recursos disponibilizados pelos sites de pesquisa. Ressaltamos que a busca de informações é umas das habilidades mais básicas dentro da competência digital, visto que uma pesquisa bem realizada leva a fontes mais seguras de pesquisa, revelando uma maior confiabilidade para a informação encontrada.

Além disso, cremos que apresentar habilidades relacionadas ao tratamento da informação não está diretamente relacionado a presença ou não de precocidade e/ou comportamento superdotado. $\mathrm{O}$ fator determinante de uma boa utilização será o desenvolvimento de competências digitais relacionadas às buscas na internet, que devem ser trabalhadas e estimuladas no contexto escolar.

Acreditamos que, em um mundo que se faz cada vez mais digital e interativo, é primordial que professores e estudantes desenvolvam competências e habilidades para utilizar as TDIC. Estas sim possuem grande potencial para tornarem-se ferramentas de aprendizagem, de uso constante, dentro dos espaços escolares quando utilizadas com intencionalidade pedagógica.

\section{REFERÊNCIAS}

AHMAD, M.; BADUSAH, J.; MANSOR, A. Z.; KARIM, A. A. The Discovery of the Traits of Gifted and Talented Students in ICT. International Education Studies, v. 7, n. 13, p. 92-101, 2014. Disponível em: <http://files.eric.ed.gov/fulltext/EJ1071179.pdf>. Acesso em: 29 dez. 2015. 
BRASIL. Ministério da Educação. Política Nacional de Educação Especial na perspectiva da Educação Inclusiva. MEC, SEEP, 2008.

BUIM ARENA, D. As metamorfoses dos modos de ler: da rua para a escola. Revista Passage de Paris, n. 10, p. 114-124, 2015. Disponível em: <http://www.apebfr.org/passagesdeparis/editione2015/articles/pdf/PP10_Dossier8.pdf $>$. Acesso em: 16 set. 2015.

COSTA, R. A cultura digital. São Paulo: Publifolha, 2002.

LUEG, C. F. Competencia digital docente: desempeños didácticos en la formación inicial del profesorado. Revista Científica de Educación y Comunicación, Educom, Cádiz-Espanha, n. 9, p. 55-71, $2^{\circ}$ semestre, nov. 2014.

MARQUES, J. A. Usos e apropriações da internet por crianças e adolescentes: análise comparativa das duas ondas da pesquisa Tic Kids Online Brasil. In: BARBOSA, A. F. (Coord.). Pesquisa sobre o uso da internet por crianças e adolescentes no Brasil: TIC Kids Online Brasil 2014. São Paulo: Comitê Gestor da Internet no Brasil, 2015. p. 7092. Disponível em: <http://www.cetic.br/publicacoes/indice/page:2>. Acesso em: 04 fev. 2016.

MONEREO, C.; AGUSTÍ, M. F. Aprender a buscar y seleccionar en Internet. In: MONEREO, C. (Coord.). Internet y competencias básicas: aprender a colaborar, a comunicarse, a participar, a aprender. Barcelona: Graó, 2010. p. 27-50.

PALFREY, J; GASSER, U. Nascidos na era digital: entendendo a primeira geração dos nativos digitais. Porto Alegre: Artmed, 2011.

PESCADOR, C. M. Alunos nativos digitais e professores imigrantes digitais. In: SOARES, E. M. S.; PETARNELLA, L. (Org.). Cotidiano escolar e tecnologias: tendências e perspectivas. Campinas: Alínea, 2012. p. 15-30.

RENZULLI, J. S. A concepção de superdotação no modelo dos três anéis: um modelo de desenvolvimento para a promoção da produtividade criativa. In: VIRGOLIM, A. M. R.; KONKIEWITZ, E. C. (Org.). Altas Habilidades/Superdotação, inteligência e criatividade. Campinas: Papirus, 2014. p. 219-264.

SANTAROSA, L. M. C.; CONFORTO, D. Formação de professores em tecnologias digitais acessiveis. Porto Alegre: Evangraf, 2012.

SANTOS, H. P. Tecnologias e mídias educativas. Belo Horizonte: Editora UFMG, 2015.

SEGÓVIA, B.; MÉRIDA, R.; GONZÁLEZ, E.; OLIVARES, M. A. Choque cultural en las aulas: profesores analógicos vs alumnado digital. El caso de Ana. EDUTEC, Revista Electrónica de Tecnología Educativa, n. 43, p. 1-12, marzo 2013. Disponível em: <http://www.edutec.es/revista/index.php/edutec-e/article/view/338/75>. Acesso em: 16 fev. 2016.

Texto recebido em 26 de janeiro de 2017. Texto aprovado em 25 de fevereiro de 2017. 